\title{
Fault plane parameters of Sanhe-Pinggu M8 earthquake in 1679 determined using present-day small earthquakes
}

\author{
Xiaoshan Wang $\cdot$ Xiangdong Feng $\cdot$ \\ Xiwei Xu • Guiling Diao • Yongge Wan • \\ Libin Wang $\cdot$ Guangqing Ma
}

Received: 10 June 2014/ Accepted: 12 September 2014/Published online: 16 October 2014

(C) The Seismological Society of China, Institute of Geophysics, China Earthquake Administration and Springer-Verlag Berlin Heidelberg 2014

\begin{abstract}
The great Sanhe-Pinggu $M 8$ earthquake occurred in 1679 was the largest surface rupture event recorded in history in the northern part of North China plain. This study determines the fault geometry of this earthquake by inverting seismological data of present-day moderate-small earthquakes in the focal area. We relocated those earthquakes with the double-difference method. Based on the assumption that clustered small earthquakes often occur in the vicinity of fault plane of large earthquake, and referring to the morphology of the long axis of the isoseismal line obtained by the predecessors, we selected a strip-shaped zone from the relocated earthquake catalog in the period from 1980 to 2009 to invert fault plane parameters of this earthquake. The inversion results are as follows: the strike is $38.23^{\circ}$, the dip angle is $82.54^{\circ}$, the slip angle is $-156.08^{\circ}$, the fault length is about $80 \mathrm{~km}$, the lower-boundary depth is about $23 \mathrm{~km}$ and the buried depth of upper boundary is about $3 \mathrm{~km}$. This shows that the seismogenic fault is a NNE-trending normal dip-slip fault, southeast wall downward and northwest wall uplift, with the right-lateral strike-slip component. Moreover, the
\end{abstract}

X. Wang · Y. Wan

Institute of Geophysics, China Earthquake Administration,

Beijing 100081, China

X. Wang · X. Feng $(\bowtie) \cdot$ G. Diao $\cdot$ L. Wang $\cdot$ G. Ma

Earthquake Administration of Hebei Province,

Shijiazhuang 050021, China

e-mail: fxd23@126.com

X. Xu

Institute of Geology, China Earthquake Administration,

Beijing 100029, China

Y. Wan

Institute of Disaster Prevention, Sanhe 065201, China surface rupture zone, intensity distribution of the earthquake and seismic-wave velocity profile in the focal area all verified our study result.

Keywords Sanhe-Pinggu $M 8$ earthquake · Present-day moderate-small earthquakes · Double-difference earthquake location - Tectonic stress field · Fault plane parameter

\section{Introduction}

An earthquake with magnitude 8.0 has occurred in SanhePinggu area, to the northeast of Beijing on Sep. 2, 1679, which was the largest surface rupture event recorded in history in the northern part of North China plain (Xu et al. 2002). The surface deformation zone of this earthquake, however, is indistinct, since the event occurred in plain area, so that the seismic fault was buried by Quaternary sediment, and it has long been reformed by natural effect and human activity. In recent years, there is a great deal of research work on the tectonic problem of this earthquake (Peng et al. 1981; Meng et al. 1983; Xiang et al. 1988). To explore the fine crustal structure and deep tectonic setting, the predecessors had carried out a series of geophysical surveying of this earthquake by means of wide-angle and deep seismic reflection profiling (Zhang et al. 2002 Zhao et al. 2004; Liu et al. 2011), electromagnetic array profiling and magnetotelluric sounding (Deng et al. 2001), seismic tomography (Yu et al. 2003; Huang and Zhao 2004; Lei et al. 2008). The detailed investigation of the crustal structure and seismotectonic of this region is very important for the understanding of physics of continental earthquakes and for the assessment and mitigation of seismic hazard. 
The seismic causal tectonic activity often originated in the deep of the crust, surface geological observations are not enough to clarify the deep crustal structure and process. The high-sensitivity seismographs are needed to draw the underground faint vibration of epicenter concentrated zone, which may be the ground trace of the deep seismic faults (Fu 1963). Large earthquakes are typically followed by aftershock activity that decays to a lower level interpreted as "normal" background seismicity. This transition is difficult to identify precisely, because defining it depends on the area treated as the aftershock zone and the criterion used (Stein and Liu 2009). Present earthquake hazard assessments typically assume that recent small earthquakes indicate the location of large future earthquakes. But what if some of these recent earthquakes are instead aftershocks of earlier large events? There was still activity of many small earthquakes after the elapse of several decades, or hundreds of years to event nearly one thousand years in many large earthquake areas, a great deal of small earthquakes usually occurs on the fault plane and its vicinity (Wang 1985). So the spatial distribution of the small earthquakes, if well located, can give a precise description of the geometry of the fault plane of historical great earthquakes. The previous studies, such as the Cixian earthquake (Diao et al. 1999), the Linfen and Hongdong earthquakes ( $\mathrm{Hu}$ et al. 2002), indicate the method that determine the $3 \mathrm{D}$ characteristics of seismic faults for historical strong earthquakes based on the present-day small earthquake clusters is proved to be feasible in practice. However, this method have not been quite quantitative, improvement on quantitative determination of fault plane using locations of small earthquakes is very much needed. Wan et al. (2008) recently developed a robust algorithm to invert the fault plane parameters of strong earthquakes on the basis of small earthquake clusters and regional stress field, which is used for the 1976 Tangshan strong earthquake sequence and estimated fault planes are close to the results of previous studies, attesting the validity of this method. Fault plane parameters of the 1668 Tancheng earthquake (Zhou et al. 2010) and the 1879 southern Wudu earthquake (Liu et al. 2012) are inverted by the method proposed by Wan et al. (2008), and the results give a precise description of the geometry of focal fault, which is proved to be an effective method for the active fault exploration and focal fault determination of historical great earthquakes.

In this paper, the fault plane parameters of the 1679 Sanhe-Pinggu M8 earthquake is determined by the algorithm proposed by Wan et al. (2008) on the basic of present-day seismological data. Combining with the surface rupture zone, tectonic structure, seismic profile and isoseismal data, the author analyzes 3D characteristics of the focal fault and the deep-shallow tectonic feature in the source region of Sanhe-Pinggu M8 earthquake.

\section{Data and method}

The area of the Sanhe-Pinggu earthquake is within the Beijing area, where the seismic network construction is early in 1966, seismic stations (black triangles in Fig. 1) are dense and data records are rich and complete. It should be particularly point out that since 2002 the digital Seismic Network of Capital Area, equipped with digital seismographs with real time data transmission capacity, has been in operation. A great deal of valuable digital records of seismic waveforms have been obtained, which provide a necessary database for studying the focal fault of SanhePinggu earthquake in 1679 (Department of Earthquake Disaster Prevention, State Seismological Bureau 1995) (red diamond in Fig. 1). On the other hand, along with the development of earthquake location technology, precisions of small earthquake locations have been greatly improved, and measurements of precisely located small earthquakes have been rapidly accumulated. All of these have made it possible to determine quantitatively the geometries of seismogenic fault in depth using small earthquake clusters.

In this paper, the authors first use the Hypo2000 algorithm (Klein 1978) to relocate the small and moderate-sized earthquakes occurred in the focal region from 1 January 1980 to 31 December 2009 with a seismic velocity model given by $\mathrm{Yu}$ et al. (2003). Then we relocated those earthquakes using the double-difference algorithm (Waldhauser and Ellsworth 2000) under the same velocity model. After removing the events whose errors are greater than $1 \mathrm{~km}$ and those too scattered to be solved effectively by double differencing, we end up with the high-precision locations of the small earthquakes, which make it possible to accurately outline the fault plane of the Sanhe-Pinggu earthquake.

It is a new algorithm proposed by Wan et al. (2008) to determine the fault plane parameters of great earthquakes on the basis of small aftershocks distribution and regional stress field. The algorithm combines global search with the simulated annealing and Gauss-Newtonian methods in its iteration for the optimal solution and also provides error estimates for the parameters. We present a mathematical model for the basic idea of this algorithm to search for a plane which minimizes the sum of the squares of the distances from the small earthquakes locations to the plane, and solve for the strike, dip and upper/lower bounds of the seismogenic fault on the basis of the fault plane. Then based on the assumption that the fault slip direction coincides with the shear stress direction of the local stress filed projected on the fault plane, the slip of fault plane can be computed from the parameters of regional stress field. 


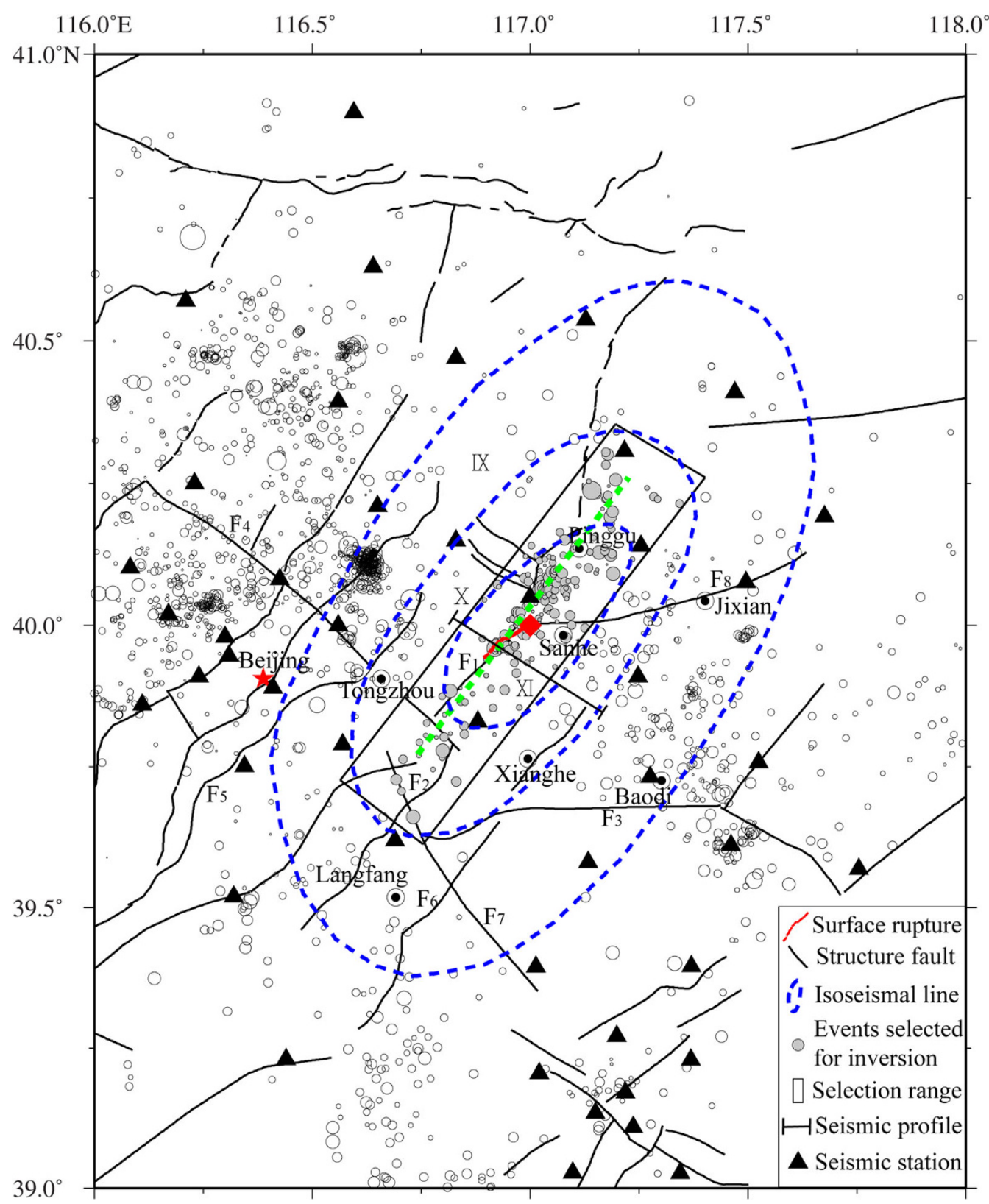

Fig. 1 Distribution of seismic stations (black triangles) used in relocation, precisely located small earthquakes and data selection range for inverting the focal fault of the Sanhe-Pinggu M8 earthquake (red diamond). F1 Xiadian Fault; F2 Eastern Marginal Fault of Daxing Uplift; F3 Baodi-Xianghe Fault; F4 Nankou-Sunhe Fault; F5 Tongxian-Nanyuan Fault; F6 Hexiwu Fault; F7 Northeastern Marginal Fault of Langfang Basin; F8 Duanjialing-Bangjun Fault

The location of the fault plane can be determined on the basis of the concentration extent of those precisely located small earthquakes. It is reasonable to believe that the same group of small earthquakes which have been used to locate the fault position can also be used to identify the periphery of the fault plane. We assume that $90 \%$ of these small events are located within the boundaries, and only $10 \%$ fall outside of the fault plane region. So we take the depth separating the uppermost $2.5 \%$ of the small earthquakes from the rest as the upper boundary, the depth separating the lowermost $2.5 \%$ of the small earthquakes as the lower boundary, the vertical line separating the leftmost $2.5 \%$ of the small earthquakes as the left boundary, and the vertical line separating the rightmost $2.5 \%$ of the small earthquakes as the right boundary of the fault plane, respectively. Therefore the four top points of the rectangular shaped fault plane for this earthquake can be determined.

To invert the parameters of focal fault, one must first know the strikes and dip angles of three principal stress axes of the local tectonic stress field, which can be obtained 
Table 1 Regional tectonic stress field of Sanhe-Pinggu (source region) and adjacent area

\begin{tabular}{llllllll}
\hline$\sigma_{1}$ & & & $\sigma_{2}$ & & & $\sigma_{3}$ & $R$ \\
\cline { 6 - 8 } \cline { 5 - 7 } & $\mathrm{Az} /{ }^{\circ}$ & $\mathrm{Az} /{ }^{\circ}$ & $\mathrm{Pl} /{ }^{\circ}$ & & $\mathrm{Az} /^{\circ}$ & $\mathrm{Pl} /{ }^{\circ}$ & \\
\hline 258 & 18 & 144 & 51 & 0 & 33 & 0.30
\end{tabular}

by deriving the tectonic stress field from the focal mechanism solutions of present-day earthquakes occurred near the focal region. Wan (2010) divide the whole China into $2^{\circ} \times 2^{\circ}$ subregions and determine the tectonic stress direction and stress ratio in each subregion using the crustal stress database in China and its adjacent areas (Xie et al. 2003) and CMT catalog (Dziewonski et al. 1981) from 1976 to 2005 . Our research area is included in one subregion. Taking into account the $M 8$ earthquake should be controlled by the tectonic stress field, and the maximum principal stress direction at the century scale is stable. So, we chose the suitable parameters of the tectonic stress field from Wan's results (2010) for this research (Table 1). These data indicate that the modern crustal stress activity is mainly horizontal movement, so the earthquakes almost belong to strike-slip type.

\section{3D characteristics of the focal fault of Sanhe-Pinggu M8 earthquake}

The range of data selection for the focal fault of SanhePinggu earthquake in shown in Fig. 1, which is determined according to the spatial distribution of precisely located small earthquake occurred on the Xiadian fault zone in combination with geological investigation. 216 small
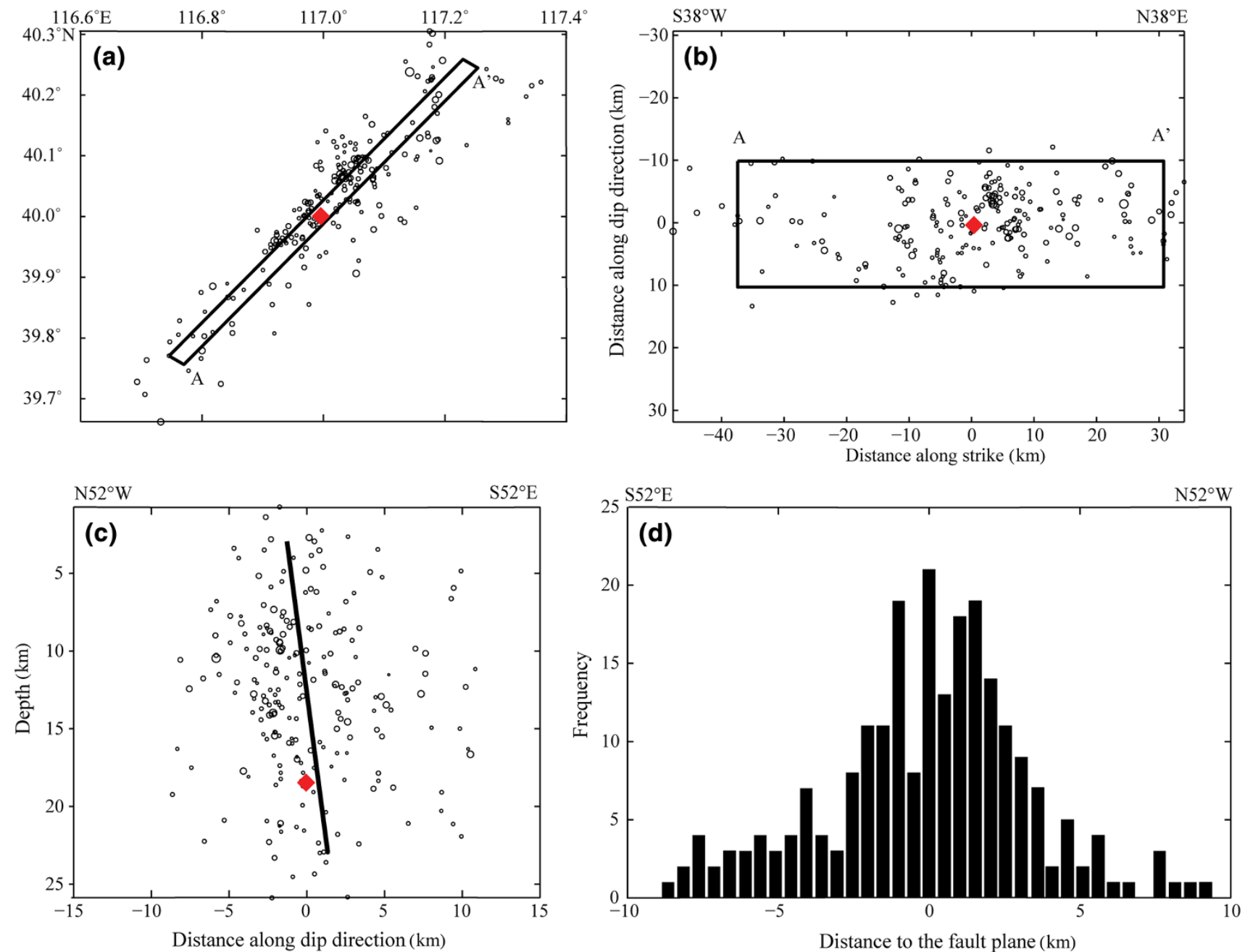

Fig. 2 Distribution of precisely located small earthquakes near the Xiadian Fault zone. a The map view; b Vertical cross-section along the fault plane; c Vertical cross-section perpendicular to the fault plane; d Histogram of small earthquakes sorted by their distances to the fault plane. The red diamond is the Sanhe-pinggu earthquake in 1679 , circles indicated the event locations, thick lines are the fault plane boundaries, $A A^{\prime}$ ' is the fault upper boundary. DD is dip; DF is distance from the fault plane; SD is strike 
earthquakes are selected for inversion and all of them are within the area of intensity X (Department of Earthquake Disaster Prevention, State Seismological Bureau 1995), which is also coinciding with the data selection range. The section where these epicenters are located is the shatter segment of seismogenic fault and also the aftershock distribution zone of Sanhe-Pinggu M8 earthquake (Fig. 1). The basic data of fault inversion are shown in Fig. 2.

The fault derived from the inversion is almost upright (Fig. 2c). Because there are more small earthquakes precisely located and the errors of fault strike and dip angle are very small, therefore, the distance distribution of small earthquakes to the inverted fault plane (Fig. 2d) shows that most small earthquakes are distributed near the derived fault plane and they are basically in a symmetrical pattern on both sides with respect to the fault plane. Nevertheless, the earthquakes located on the southeast side immediately near the fault plane are slightly more in number.

The major parameters of fault inversion result are listed in Table 2. The least squares fitting values of strike angle, dip angle, and distance to the origin are $38.23^{\circ}, 82.54^{\circ}$, and $0.006 \mathrm{~km}$, respectively, with the standard error of $0.93^{\circ}$, $2.80^{\circ}$, and $0.26 \mathrm{~km}$; and it means that the strike of the inverted fault plane is $38.23^{\circ}$ and the dip angle is $82.54^{\circ}$. The coordinate locations of the four vertexes of the fault plane are shown in Table 2. The calculated slip angle of the fault plane is $-156.08^{\circ}$ and the residual is $5.81^{\circ}$. The fault is almost upright and its length is about $80 \mathrm{~km}$. Its dislocation is characterized by right-lateral strike-slip with a little bit normal fault as well.

\section{Comparative analysis of the focal fault, tectonic fault, surface rupture and intensity distribution}

According to the above inversion result, the 1679 SanhePinggu $M 8$ earthquake was a high-dip strike-slip dislocation. The strike of focal fault was about $38.2^{\circ}$ and the dip angle was about $82.5^{\circ}$, slightly dipping toward the southeast. The slip angle was about $-156^{\circ}$. The fault length was about $80 \mathrm{~km}$, the lower-boundary depth was $23 \mathrm{~km}$, the buried depth of upper boundary was about $3 \mathrm{~km}$, and the lower boundary of predominant depth of present-day small earthquakes was about $20 \mathrm{~km}$.

The 1679 Sanhe-Pinggu $M 8$ earthquake is the latest surface rupture event occurred on the New Xiadian Fault, which is the boundary fault between Dachang depression and Daxing uplift. The surface rupture zone (red line in Fig. 1) of this great earthquake initiated from Dongliuhetun and extends toward northeast through Pangezhuang, Qixinzhuang, to Dongxingzhuang area, generally striking $\mathrm{N} 40^{\circ}-45^{\circ} \mathrm{E}$, having a total length of $10 \mathrm{~km}$ or more. It consists of left-handed arrangement of several NE-ENE

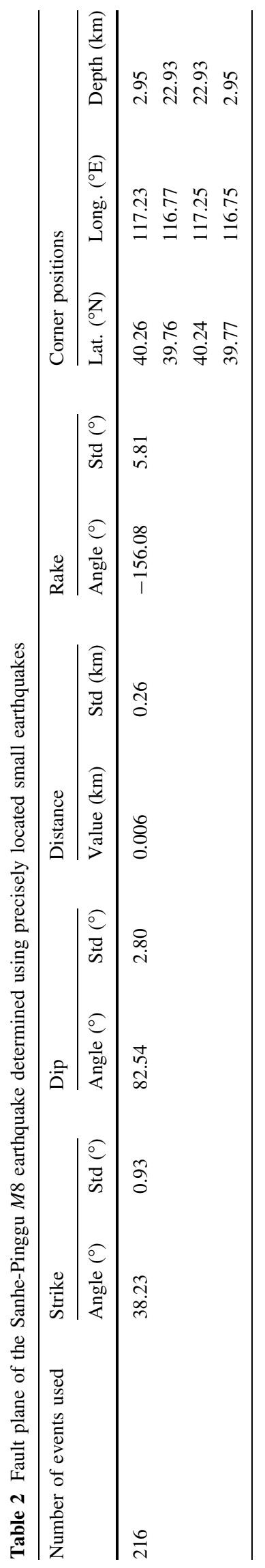




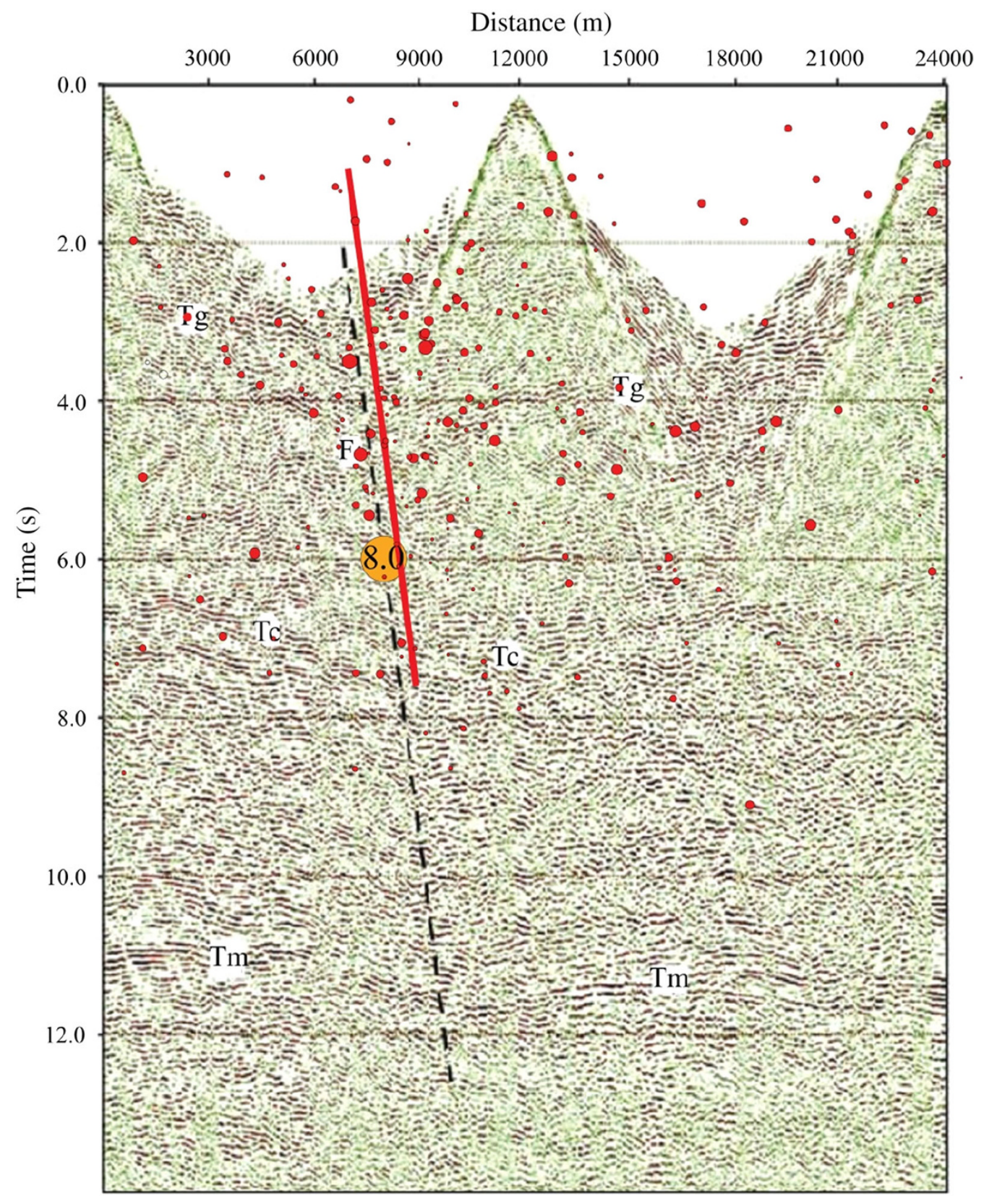

Fig. 3 Velocity structure obtained by single-fold reflection section (Liu et al. 2011), present-day small earthquakes (red solid circles) and projection (red line) of the focal fault of the Sanhe-Pinggu M8 earthquake. The yellow circle is the hypocenter of M8 earthquake. The dash line denotes the New Xiadian Fault (F1)

trending fault scarps, knick bands of topographic slopes and fault sags, forming a surface fracture zone characterized by dextral tensile-share dislocation (Xiang et al. 1988). These indicate this earthquake belongs to normal dip-slip fault type, southeast wall downward and northwest wall uplift, with the right-lateral strike-slip component (Peng et al. 1981; Meng et al. 1983; Xiang et al. 1988). The slip angle of fitted focal fault is $-156^{\circ}$, which show a right-lateral strikeslip dislocation with a little bit normal fault as well. It is basically coincident with the geological investigated results.
The long axis strike of isoseismal line is NNE, which is consistent with the strike of New Xiadian Fault, surface rupture zone (Fig. 1) and the projection of focal fault (green ling in Fig. 1), which deviated toward northwest. Through precise relocation, small cluster is within the area of intensity X. The data fitting on the basis of moderatesmall earthquakes occurred in the present day is to suppose the seismogenic fault of historical great earthquakes still has inheritance activities at present and they still occur on the fault plane of that great earthquake or on the rock mass 
of both sides. The fitted results are distributed in the range of $3-23 \mathrm{~km}$ and the constraint for the shallow stratum is not strict. Since the events are not completely homogenously distributed on the whole fault plane, fine division is not made in details.

To understand the fine deep-shallow tectonic feature, Liu et al. (2011) carried out a single-fold deep seismic reflection profiling and a shallow seismic reflection profiling (Fig. 3) in the Sanhe-Pinggu earthquake source region. The seismic reflection profile reveals that the deep fault in crust coincides well with the active fault in the shallow subsurface, the deep fault has a larger dip angle, which is parallel to the focal fault, and extends upward into the upper crust, and joins the crustal deep structure to the shallow active fault. The interface reflect wave between the upper and lower crust Tc at the two-way travel-time $7 \mathrm{~s}$ is about $20-21 \mathrm{~km}$ deep. The interface acts as a transitional zone between the brittle upper crust and the ductile lower crust, and plays a role to transmit energy and decouple between them. Strain energy is liable to accumulate and release in the location with this kind of velocity and great earthquake is prone to occur here. The lower boundary of the focal fault is located on the interface, seismicity (red solid circles in Fig. 3) just terminated here. The focal fault was projected on the seismic profile; the focal fault (red line in Fig. 3) deviated southeast toward the deep fault revealed by the deep seismic reflection profile. Therefore, it has indirectly proved that the location of the focal fault determined in this paper is reasonable.

\section{Discussion and conclusions}

In this paper, we successfully inverted the seismic fault plane parameters of Sanhe-Pinggu M8 great earthquake based on spatially clustered small earthquakes occurred in the source region with the algorithm proposed by Wan et al. (2008). The fault rupture parameters match the results of previous studies constrained by different dataset. So the authors suggest that although Sanhe-Pingu earthquake occurred more than 300 years ago, the present-day small earthquakes near the focal region can also precisely determine the geometry of this great earthquake fault. The inversion result is a right-lateral strike-slip dislocation of the high-dipping fault, which has a strike of $38.2^{\circ}$ and a length of $80 \mathrm{~km}$. Tilting slightly to the SE, the fault is nearly upright with a slip angle of $-156^{\circ}$ and a little bit normal dip-slip. The lower-boundary depth of the fault is $23 \mathrm{~km}$; the berried depth of the upper boundary is about $3 \mathrm{~km}$. The inverted result is verified to be reliable by the data from geological investigation and deep seismic reflection profile. However, the inverted length of the seismic fault is longer than that determined by the geological investigation on the basis of surface fracture, which is coincident with the rupture length of a $M 8$ earthquake.

In recent years, with the improvement of digital seismic observation technology and wide deployments of digital seismic networks, the capability of earthquake monitoring has been improved significantly and the seismic phase pickings have become more and more accurate. More interests have grown in using spatial distributions of small earthquakes to detect tectonic structures and solve for related geophysical problems. Analyzing the 3D characteristics of precisely located present-day moderate-small earthquakes occurred in the source region of historical strong earthquake, the authors consider that the present epicentral locations are coincident to the distribution pattern of main shock and aftershocks of $M 8$ strong earthquakes. It means that the supposition is tenable that the moderate-small earthquakes in the region of historical strong earthquake are the inheritance activities on the fault plane or on the rock masses of both sides of the historical great earthquake. Therefore, the characteristics of the source volume of the great historical earthquakes can be determined by the spatially clustered small earthquakes. Attempt to estimate the spatial orientation and move pattern of the focal fault based on the present-day seismological data, it is useful in understanding the seismogenic structure of historical earthquakes. In particular, using seismic data collected from projects of active fault detection in urban areas, one can apply this method and independently determine geometries of active faults from a large number of precisely located small earthquakes, and further obtain mechanical properties of the faults using the local stress field parameters. The authors can conclude that this method is of referential significance for the similar research in the future.

Acknowledgments This work is jointly supported by the National Natural Science Foundation of China (Nos. 91214201 and 41074072) and Research Foundation of Science and Technology Plan Project in Hebei Province (12276903D). All of figures are plotted by using the GMT (Wessel and Smith 1995).

\section{References}

Deng QH, Wang JJ, Tang J, Zhan Y, Sun J, Li GS, Xiao SD, Hong F, Ye Q (2001) Electrical structures of the crust and upper mantle in Sanhe-Pinggu $M 8$ earthquake area China. Seismol Geol 23(2):178-185 (in Chinese with English abstract)

Department of Earthquake Disaster Prevention, State Seismological Bureau (1995) Historical strong earthquake catalogue in China (from 23 Century B. C. to A. D. 1911). Seismological Press, Beijing, pp 1-473 (in Chinese)

Diao GL, Zhang SC, Zhao J, Wang ZJ, W JG (1999) The focal faults of historical great earthquake inferred based on current small shocks: Taking an example of 1830 Cixian, Hebei, $M 7^{1 / 2}$ 
earthquake. Seismol Geol 21(2):121-126 (in Chinese with English abstract)

Dziewonski AM, Chou TA, Woodhouse JH (1981) Determination of earthquake source parameters from waveform data for studies of global and regional seismicity. J Geophys Res 86:2825-2852. doi:10.1029/JB086iB04p02825

Fu CY (1963) Several problems about earthquake prediction. Chin Sci Bull 3:30-36 (in Chinese with English abstract)

Hu XL, Diao GL, Gao JC, Zhang SJ, Chuai YQ, Duan YR, Zhao YP, Liu SG, Zhu ZX, Zhang YQ, Qin QJ (2002) Application of present small earthquakes to infer the focal faults of two large historical earthquakes in Hongdong and Linfen, Shanxi Province. Earthq Res China 18(3):76-85 (in Chinese with English abstract)

Huang J, Zhao D (2004) Crustal heterogeneity and seismotectonics of the region around Beijing, China. Tectonophysics 385:159-180

Klein F W (1978) Hypocenter location program HYPOINVERSE Part I: Users guide to versions1, 2, 3 and 4. U S Geol Surv, Open-File Rept, 78-694

Lei JS, Xie FR, Lan CX, Xing CQ, Ma SZ (2008) Seismic images under the Beijing region inferred from $\mathrm{P}$ and $\mathrm{PmP}$ data. Phys Earth Planet Inter 168:134-146

Liu BJ, Zhang XK, Chen Y, Feng SY, Ji JF, Zuo Y (2011) Research on crustal structure and active fault in the Sanhe-Pinggu Earthquake (M8.0) Zone based on single-fold deep seismic reflection and shallow seismic reflection profiling. Chin J Geophys 54(5):1251 (in Chinese with English abstract)

Liu BY, Yuan DY, Zhang B, Chen WK, Niu YP (2012) Determination of fault parameters and sliding behavior of the 1879 southern Wudu M8.0 earthquake. Seismol Geol 34(3):415-424 (in Chinese with English abstract)

Meng XL, Du CT, Wang R, Liu SP (1983) Rupture of the SanhePinggu earthquake of 1679. Earthquake 3(3):18-23 (in Chinese with English abstract)

Peng YM, Li DR, Xie ZZ, Wang AD, Liu QS (1981) Some features of contemporaneous faults in Beijing plain and their significance. Seismol Geol 3(2):57-64 (in Chinese with English abstract)

Stein S, Liu M (2009) Long aftershock sequences within continents and implications for earthquake hazard assessment. Nature 462:87-89

Waldhauser F, Ellsworth WL (2000) A double-difference earthquake location algorithm: method and application to the Northern
Hayward fault, California. Bull Seismol Soc Am 90(6): 1353-1368

WanY G (2010) Contemporary tectonic stress field in China. Earthq Sci 23:377-386

Wan YG, Shen ZK, Diao GL, Wang FC, Hu XL, Sheng SZ (2008) An algorithm of fault parameter determination using distribution of small earthquakes and parameters of regional stress field and its application to Tangshan earthquake sequence. Chin J Geophys 51(3):793-804 (in Chinese with English abstract)

Wang ZG (1985) The "long-term activity" of large earthquake areas. Acta Seismol Sin 7(3):254-266 (in Chinese with English abstract)

Xiang HF, Fang ZJ, Xu J, Li RC, Jia SF, Hao SJ, Wang JB, Zhang WX (1988) Seismotectonic background and recurrence interval of great earthquakes in 1679 Sanhe-Pinggu $M=8$ earthquake area. Seismol Geol 10(1):15-28 (in Chinese with English abstract)

Xie FR, Chen QC, Cui XF, Li H, Yang SX, Guo QL, Chen LW, Xu ZH, Zhang YS, Dou SQ, Zhao JT, Zhang ZS, Liu CY, Wang GJ (2003) Database of crustal stress in China and its adjacent areas. In: Chen QC, Cui XF, Li H, Yang SX, Chen LW (eds) Crustal stress in China. Geological Press, Beijing, pp 3-12 (in Chinese with English abstract)

Xu XW, Wu WM, Zhang XK, Ma SL, Ma WT, Yu GH, Gu ML, Jiang WL (2002) The latest crustal deformation and earthquakes in Beijing area. Seismological Press, Beijing, pp 118-133 (in Chinese)

Yu XW, Chen YT, Wang PD (2003) Three-dimensional P wave velocity structure in Beijing-Tianjin-Tangshan area. Acta Seismol Sin 25(1):1-14 (in Chinese with English abstract)

Zhang XK, Zhao JR, Liu GH, Song WR, Liu BJ, Zhao CB, Cheng SX, Liu JD, Gu ML, Sun ZG (2002) Study on fine crustal structure of the Sanhe-Pinggu earthquake (M8.0) region by deep seismic reflection profiling. Earthq Res China 18(4):326-336 (in Chinese with English abstract)

Zhao JR, Zhang XK, Zhang CK, Zhang JS, Yang ZX, Liu BF, Liu BJ, Zhao CB (2004) Deep structural features of the Sanhe-Pinggu great earthquake area imaged by wide-angle and deep seismic reflection profiling. Chin J Geophys 47(4):646-653 (in Chinese with English abstract)

Zhou CY, Diao GL, Geng J, Li YH, Xu P, Hu XL, Feng XD (2010) Fault plane parameters of Tancheng $M 8^{1 / 2}$ earthquake on the basis of present-day seismological data. Earthq Sci 23:567-576 